\title{
A 3 Year Study of Rupture Uterus at a Tertiary Hospital
}

\author{
Authors \\ Dr Vinita Bansal ${ }^{1}$, Dr Pooja Saini ${ }^{2}$ \\ ${ }^{1}$ Junior Specialist Cum Clinical Tutor, M.S. Obs . \& Gyn. Govt. Medical College Kota \\ (Rajasthan) \\ Email:-Pawanbansalkota@Yahoo.Com \\ ${ }^{2}$ Second Year Resident, Department Of Obs. \& Gyn. Govt. Medical College, Kota (Rajasthan), \\ Email:-drpoojasaini10@gmail.com
}

\begin{abstract}
Objectives: To evaluate risk factors, type and site of rupture, management, maternal and perinatal outcome and to identify preventive measures at our institute.

Methods: A retrospective study carried out at Government medical college and hospital, Kota. The details of 50 cases of complete uterine rupture managed between January 2013 and December 2015 were reviewed.

Results: There were 50 cases of ruptured uterus out of total 35,946 deliveries (including 12,642 cesarean section) over a period of three years with prevalence of 0.13\%.The most common age group was 21-30 years .35(70\%) cases of uterine rupture occurred in scarred uterus while 15(30\%)cases occurred in unscarred uterus. The main contributing factor to uterine rupture identified in this study, was poor antenatal care.
\end{abstract}

\section{Introduction}

Uterine rupture is an obstetrical emergency endangering life of both mother and fetus. It is a grave condition which is almost fatal for fetus ${ }^{1}$. Several factors are known to increase the risk of ruptured uterus. These include poor socioeconomic condition, uncontrolled fertility, illiteracy, adolescent marriage and underdeveloped and contracted pelvis ${ }^{2}$. Uterine rupture during pregnancy is a rare occurrence, where as uterine scar dehiscence is a more common event ${ }^{3}$. Due to lack of health education, ignorance or poverty women in our country do not come for regular antenatal checkup, preferring home delivery by traditional birth attendant instead of coming to hospital. They are brought to hospital after prolonged dysfunctional labour when traditional birth attendant fail to deliver Repair of uterus was done in $40(80 \%)$ cases, in 12 cases tubal ligation was also done and subtotal hysterectomy was done in $9(18 \%)$ cases and one patient died undelivered. Bladder was injured in $3(6 \%)$ cases. There were 3 (6\%) maternal deaths and $39(78 \%)$ perinatal deaths.

Uterine rupture is a major risk factor for maternal and perinatal morbidity and mortality Proper 
antenatal care, timely referral of women at risk, and repeat cesarean section in parturients with previous uterine scar ,especially when labor fails to progress ,would improve maternal and perinatal outcome. them, the result is a chance of rupture uterus and as well as rupture of previous caesarian scar $^{4}$. High maternal mortality and morbidity is a consequence of poor maternal care, inadequate socioeconomic and environmental condition, poor accessibility to health services and poor nutrition ${ }^{5}$. The objective of the study is to determine the incidence, etiology, trend, management and maternal and fetal outcome of ruptured uterus and to identify the preventive measures.

\section{Material and Method}

This is a retrospective study of patients with complete ruptured uterus from the period of January 2013 to december 2015 admitted in
Government Medical College, Hospital, Kota. Total number of deliveries during the period was 35,946. All the cases of ruptured uterus during study period were included in this study. Patients were initially assessed in labour ward, relevant sociodemographic data, previous antenatal obstetric history, period of gestation, duration of labour pain, history of delivery attendant were recorded.

\section{Results}

A total 50 cases of ruptured uterus were recorded from January 2013 to December 2015. Total deliveries were 35,946. Prevalence of ruptured uterus was $0.13 \%$. Age of patients ranged from 15 40 years. Most of the patients were in the age of 2130 years i.e. 36 patients $(72 \%)$ (Table I) There were only two primigravida who had rupture of uterus, majority of rupture uterus occur in para 2 i.e 24 (48\%) cases (Table 2).

Table 1: age-wise distribution of patients

\begin{tabular}{|l|l|l|}
\hline Age & No of cases & Percentage \\
\hline $15-20$ & 2 & 4 \\
\hline $21-25$ & 15 & 30 \\
\hline $26-30$ & 21 & 42 \\
\hline $31-35$ & 9 & 18 \\
\hline $35-40$ & 3 & 6 \\
\hline Total & 50 & 100 \\
\hline
\end{tabular}

Table 2: parity-wise distribution of patients

\begin{tabular}{|l|l|l|}
\hline Parity & No of cases & Percentage \\
\hline 1 & 2 & 4 \\
\hline 2 & 24 & 48 \\
\hline 3 & 14 & 28 \\
\hline 4 & 4 & 8 \\
\hline$\geq 5$ & 6 & 12 \\
\hline Total & 50 & 100 \\
\hline
\end{tabular}

Table 3 shows most occurrences of ruptured uterus was amongst the gestational age 37- 40 weeks, total $39(78 \%)$ at this age, 4 cases at $29-32$ weeks, 4 at 33 36 weeks, 2 at 28 weeks and 1 at 18 week. Majority of the patients were illiterate $33(66 \%)$. Most of the patients came from remote villages i.e. $41(82 . \%)$ and rest from urban area. 
Table 3: Gestation age(weeks) of patients

\begin{tabular}{|l|l|l|}
\hline Gestation age & No of cases & Percentage \\
\hline$\leq 28$ weeks & 3 & 6 \\
\hline $29-32$ weeks & 4 & 8 \\
\hline $33-36$ weeks & 4 & 8 \\
\hline $37-40$ weeks & 39 & 78 \\
\hline Total & 50 & 100 \\
\hline
\end{tabular}

Most cases of rupture i.e 70\%occur in patients with previous scar and most of them were reffered from periphery, some had history of handling from dais almost all were in active labour with diagnosed rupture at time of admission. One patient with previous 2 cesarean had irreparable rupture in 18 weeks gestation. In 14 cases rupture occured due to cephalopelvic disproportion, malpresentation, and multiparity. majority of these also had trial of labour before admitting to hospital. In $1(2 \%)$ case rupture was due to iatrogenic cause due to induction of labour with misoprostol at 26 weeks of gestation (table 4)

Table 4: Risk factor for rupture uterus

\begin{tabular}{|l|l|l|}
\hline Risk factor & No of cases & Percentage \\
\hline a)Scarred uterus & 35 & 70 \\
\hline prev.1C.S. & 30 & 60 \\
\hline prev.2C.S. & 3 & 6 \\
\hline prev.3C.S. & 2 & 4 \\
\hline b)Unscarred uterus & 15 & 30 \\
\hline Obstructed labour & 9 & 18 \\
\hline malpresentation & 4 & 8 \\
\hline induction & 1 & 2 \\
\hline Uterine anomaly & 1 & 2 \\
\hline
\end{tabular}

Out of the 50 patients, the rupture was confined to previous scar $17(34 \%)$. In 6 patients (12\%) lower segment ruptured, rupture extended to upper segment and lateral extension in $26(42 \%)$ patients, 1 patient had rupture of accessory horn of uterus.
$3(6 \%)$ patients had injury to the urinary bladder, 2(4\%)patients develop broad ligament hematoma 1 patient had perforated large intestine along with rupture uterus (Table 5)

Table 5: Site of rupture

\begin{tabular}{|l|l|l|}
\hline Site of rupture & No of cases & Percentage \\
\hline Scar & 17 & 34 \\
\hline Lower segment & 6 & 12 \\
\hline Up.and lat.seg & 26 & 52 \\
\hline Broad ligament hematoma & 3 & 6 \\
\hline Bladder injury & 3 & 6 \\
\hline Accessory horn & 1 & 2 \\
\hline
\end{tabular}

Of the 50 patients total 29patients (58\%) had no antenatal checkup. 16 patients $(32 \%)$ had irregular antenatal checkup and 5 (10\%) patients had history of regular antenatal checkup 


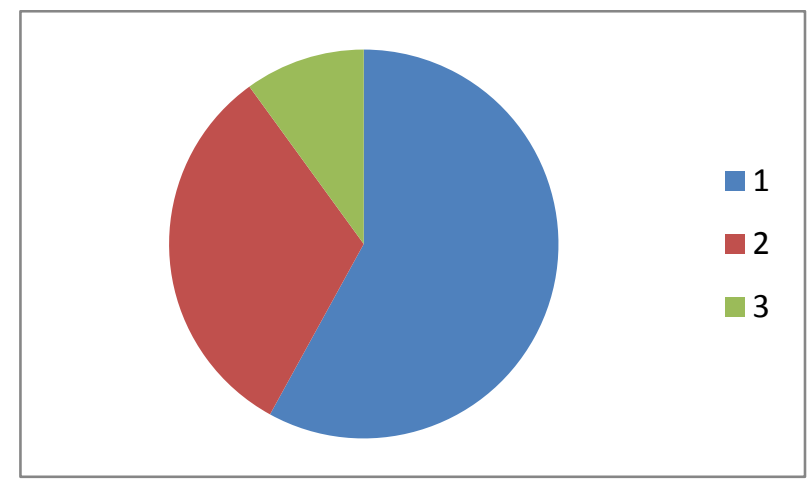

Figure : Pattern of management

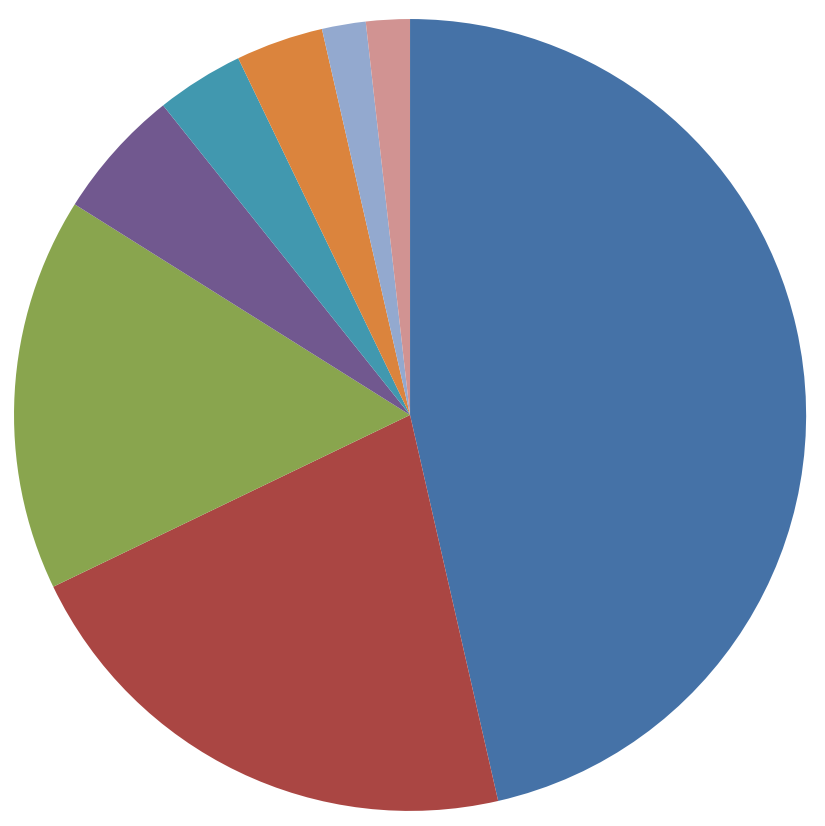

repair without stz

repair with stz

hysterctomy

- bladder repair

b lynch suture

uterrine A.lig

- end colostomy

expire before ot
Most of the patients 40 (80\%) underwent repair of rupture, tubectomy done in 13 patients, 9(18\%) underwent subtotal hysterectomy and 3 patients need repair of urinary bladder and in 2 patient $B$ lynch sutures were applied, uterine artery ligated in 2 patients. In one patient end colostomy was done because of perforated large intestine. One patient died before laprotomy.

\section{Discussion}

Ruptured uterus still remains one of the serious obstetric complications. Lack of health information, illiteracy, poor antenatal care, poverty, home delivery by traditional birth attendants and delay in referrals all contributes to uterine rupture ${ }^{4}$. Prevalence of uterine rupture in the present study is
$0.13 \%$. This study was similar to study done by Malik HS ${ }^{4}$. However the incidence is higher in a study done by Alam et $\mathrm{al}^{6}$ who had a figure of $1.14 \%$. In developing countries like in Ethiopia and Nigeria it is $0.03 \%$ and $0.83 \%$ respectively ${ }^{7,8}$. Studies conducted in developing countries gives strong evidence that uterine rupture is a major health problem in developing countries, with the rate higher in rural areas ${ }^{9,10}$. The studies also revealed that socioeconomic condition along with poor health services play a major role in determining the incidence of rupture.

Most of the patients in this study $36(72 \%)$ were between the age of 21-30 years, which was compared with of Khan et $\mathrm{al}^{11}$, where most of the women belonged to the age 31-35 years (47\%). 
Majority of the ruptured occurred in para 224 (48\%), and Malik $\mathrm{HS}^{4}$ found $42.7 \%$ in para (2-4). Majority of the patients were unbooked 45(90\%) and with irregular antenatal checkup or no antenatal checkups, $10 \%$ booked cases also do not have regular visits and similar results were found in other studies $^{4,10}$. Most of the unbooked patients were taken to the hospital from remote area. Injudicious use of oxytocin and trial of labour was the common cause, whereas prolonged obstructed labour was the second common cause. This is similar to the study of Malik $\mathrm{HS}^{4}$ and others where rupture of previous caesarian scar was the most common cause ${ }^{12}$. In this study 6 patients had rupture in the lower segment and 26 had extension in the upper and lateral segment segment, 3 had injury to urinary bladder. Subtotal hysterectomy was done in 9 patients, repair of uterus in 40 patients and repair of urinary bladder in 3 cases. 1 patients were not explored as the patients expired during resuscitation, two patient died postoperatively.. The rest 47 patients (94\%) improved. Perinatal mortality was $39(78 \%)$ which is similar to the study of Nawsaba et $\mathrm{al}^{13}$.

\section{Conclusion}

Lack of antenatal care, inappropriate counseling of patients with history of previous caesarian section for hospital delivery, delivery by untrained dai, misuse of oxytocin and delay in seeking management are the main cause of ruptured uterus in this study. In this study rupture was significantly high among para 2 patients denoting the mismanaged labour management still now.

\section{References}

1. Kulkarni S, Patil S, Budihal D, Seetaram S. Rupture uterus: A 10 years review. J Obstet Gynae. 1997; 47: 344-52.

2. Sieck CC. Vaginal birth after cesarean section: a comparison of rural and metropolitan rates in Oklahoma. Jokla State Med Assoc.1997; 90:444-9.
3. Bashin A, Burstein E, Rosen S, Smolin A, Shiner E, Mazor M. Clinical Significance of uterine scar dehiscence in women with previous caesarean delivery: Prevalence and independent risk factors. J Reprod Med. 2008; 53:8-14.

4. Malik HS. Frequency, Predisposing factors and fetomaternal outcome in uterine rupture. J Coll Physicians Surg Pak. 2006; 16:472-5.

5. Dhaifalah I, Santavy J, Fingerova H. Uterine rupture during pregnancy and delivery among women attending the Al-thawra Hospital in Sana/A city of Yemen republic. Biomed Pap Med Fac Univ Palacky Olomouc Czech Repub. 2006; 150:279-83.

6. Alam I, Khan A, Ahmed R, Begum N. A Two Year Review of Uterine Rupture at Gynaecology Unit-Ayub Teaching Hospital. J Ayub Med Coll Abottabad 2000; 12:21-2.

7. Ekpo EE. Uterine rupture as seen in the University of Calaber Teaching Hospital, Nigeria: a five -year review. J Obstet Gynaecol. 2000; 20:154-6.

8. Lynch JC, Pardy JP. Uterine rupture and scar dehiscence. A five year survey. Anaesth Intensive care 1996; 24:699-704.

9. UNICEF. The state of the Worlds Children Report Oxford University, Press New York,1996.

10. Hasan JA, Zaki M, Kareem K. Rupture of gravid uterus. J Surg Pak. 2005; 10:20-2

11. Khan S, Parveen Z, Begum S, Alam I. Uterine rupture: A review of 34 cases at Ayub Teaching Hospital Abottabad. J Ayub Med Coll Abottabad 2003; 15:50-2.

12. Gul A. Rupture of previously scarred uterus. Ann king Edward Med Coll. 2004;10:573-5.

13. Rashmi, Radhakrisknan G, Valid NB, Agarwal N. Rupture uterus changing Indian scenario. J Indian Med Assoc. 2001; 99:6347. 